\title{
In vivo Administration of Testosterone Propionate in Cattle Analyzed by High Performance Liquid Chromatography-Tandem Mass Spectrometry: An Enzymatic Hydrolysis Study and Drug Abuse Issues
}

\author{
Diego G. Rocha, ${ }^{\circledR a, b}$ Mary Ane G. Lana, ${ }^{a}$ Adriana F. Faria, ${ }^{\circledR b}$ \\ Rodinei Augusti ${ }^{\circledR b}$ and Débora C. S. de Assis ${ }^{\circledR *, c}$ \\ ${ }^{a}$ Laboratório Federal de Defesa Agropecuária (LFDA-MG), Av. Rômulo Joviano, s/n ${ }^{o}$, \\ 33600-000 Pedro Leopoldo-MG, Brazil \\ ${ }^{b}$ Departamento de Química, Instituto de Ciências Exatas, Universidade Federal de Minas Gerais (UFMG), \\ Av. Antônio Carlos, 6627, 31270-901 Belo Horizonte-MG, Brazil \\ ${ }^{c}$ Escola de Veterinária, Universidade Federal de Minas Gerais (UFMG), \\ Av. Antônio Carlos, 6627, 31270-901 Belo Horizonte-MG, Brazil
}

\begin{abstract}
This study involved an animal experiment in which testosterone propionate was intramuscularly injected into four steers, and the ensuing urine samples were analyzed using high-performance liquid chromatography-tandem mass spectrometry. The enzymatic hydrolysis conditions were analyzed using analysis of variance (ANOVA) and response surface methodology employing a $3^{3}$ Box-Behnken design. A survey study was performed in which 48 urine samples were collected from eight untreated steers to estimate the endogenous levels of testosterone metabolites, and it was found that $17 \beta$-testosterone was not detected in the majority of the samples, whereas $17 \alpha$-testosterone was present in 43 of the 48 . Drug abuse was identified within 11 days of $17 \beta$-testosterone administration. The ratio between both isomers was also assessed; however, a cut-off limit based on an untreated population could not be estimated due to the absence of the beta isomer. Therefore, there may be a correlation between the exogenous use of testosterone in castrate animals and high levels of $17 \beta$-testosterone, although confirmation through further investigation would be required.
\end{abstract}

Keywords: testosterone, livestock, animal experimentation, Box-Behnken design

\section{Introduction}

Although the use of steroids as growth promoters in foodstuffs is prohibited in the European Union and commercial partners, other countries such as Australia, Canada, New Zealand, and the United States allow their usage for these purposes. To monitor these substances from a surveillance perspective, a range of matrices must be included in regulatory plans, and urine is generally the matrix of choice. ${ }^{1-3}$

However, analytical results concerning to the presence of endogenously occurring steroids (boldenone, estradiol, nortestosterone, and testosterone) demand additional strategies such as the use of gas chromatography-

*e-mail: debora@ vet.ufmg.br

Editors handled this article: Eduardo Carasek and Emanuel Carrilho (Associate) combustion-isotope ratio mass spectrometer systems (GC-C-IRMS), ${ }^{4}$ omic approaches, ${ }^{5,6}$ intact steroid ester detection in hair/plasma, ${ }^{7,8}$ or longitudinal monitoring of biomarkers. ${ }^{910}$ As limiting factors, the first alternative has poor sensitivity and high acquisition/maintenance costs, which prevents its widespread use. Omic approaches still lack a legal framework to support a decision-making process regarding non-compliant samples, and the detection of intact steroid esters usually occurs over a short detection window. ${ }^{11,12}$ However, biomarkers have been demonstrated to be efficient alternatives, since the concomitant determination of parent drugs and their metabolites frequently leads to improved analytical detection. The steroid $17 \alpha$-testosterone ( $\alpha \mathrm{TE}$ ) is the main metabolite of $17 \beta$-testosterone ( $\beta$ TE) in human and bovine urine and the $\beta \mathrm{TE} / \alpha \mathrm{TE}$ ratio (T/E ratio), is widely used in human doping analysis. ${ }^{13,14}$ Exogenous administration of commercial 
testosterone formulations causes an increased excretion rate of urinary $\beta \mathrm{TE}$ and decreased excretion rate of $\alpha \mathrm{TE}$ resulting in an overall increase in the T/E ratio. However, false-negative results should be carefully considered, since individual metabolic patterns may be correlated with abnormal T/E ratios. ${ }^{15}$

Veterinary administration of testosterone can be conducted in animals using ear implants through which low doses are continuously released into the bloodstream, or via multiple intramuscular injections. With the latter method, sequenced concentration loops could lead to a cumulative effect (plateau effect). ${ }^{16}$ Once circulating in the organism, $\beta$ TE undergoes extensive phase I metabolism (17-oxidation, A-ring reduction, and 3-reduction) mainly in the liver. In phase II metabolism, testosterone is conjugated with glucuronic acid (glucuronidation), and to a lesser extent with 3'-phosphoadenosine 5'-phosphosulfate (PAPS) (sulfoconjugation). ${ }^{13}$ Steroid compounds are predominantly excreted in the urine from these reactions as glucuronides or sulfates. Most published protocols use enzymatic hydrolysis for detecting unconjugated steroids in this matrix, such as with $\beta$-glucuronidase from bovine liver, ${ }^{17}$ E. coli ${ }^{18}$ preparations from abalone entrails, ${ }^{18,19}$ and the frequently used Helix pomatia juice, for its activity for both glucuronides and sulfates. ${ }^{16,20}$ Usually, $\mathrm{pH}$ is maintained at approximately 5.2; however, other reaction conditions are not standardized, since reaction time varies from 2 to $24 \mathrm{~h}$, temperature from 37 to $55^{\circ} \mathrm{C}$, and enzyme volume from 25 to $50 \mu \mathrm{L} .^{12,21}$ The best reaction conditions are generally compound-dependent, ${ }^{17}$ and some glucuronides and sulfates are known to be resistant to enzymatic hydrolysis. ${ }^{22,23}$

Considering the veterinary use of testosterone, the endogenous origin of $\beta \mathrm{TE}$ and $\alpha \mathrm{TE}$ is indisputable. The presence of $\alpha \mathrm{TE}$ was observed in the urine of 294 bovines, whereas the detection of $\beta$ TE was intensified for older bulls, as was the T/E ratio. ${ }^{24}$ In the study, ${ }^{24}$ no urinary testosterone was found in animals under the age of 5 months, where the limit of quantification (LOQ) for both testosterone metabolites was $2.0 \mu \mathrm{g} \mathrm{mL}{ }^{-1}$. In another study, ${ }^{15}$ testosterone enanthate was intramuscularly administered to 9 calves at the age of 6 months and 12 were kept as a control group. The untreated animals showed variations in the T/E ratio in the range of 8-15 while the treated calves revealed values varying from 12-24. The LOQ for both testosterone metabolites was $0.5 \mu \mathrm{g} \mathrm{L}^{-1}$. The authors ${ }^{15}$ attributed the high $\alpha$ TE levels to the strong $17 \alpha$-hydroxysteroid oxidoreductase activity in calves, which catalyzed a rapid conversion of $\beta$ TE to $\alpha \mathrm{TE}$, masking the effects of the exogenous administration of testosterone. Urine samples of 200 geldings were analyzed by liquid chromatography tandem mass spectrometry (LC-MS/MS) in order to evaluate the T/E ratio in a random population not subject to drug treatment. ${ }^{14}$ For 15 of the 200 analyzed samples the concentration of $\beta$ TE exceeded the limit of $15 \mathrm{ng} \mathrm{mL}^{-1}$ $\left(\mathrm{LOQ}=1.6 \mu \mathrm{g} \mathrm{L}^{-1}\right.$ ), and the $\mathrm{T} / \mathrm{E}$ ratios were lower than

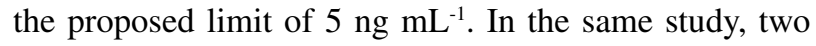
geldings (one 7-year-old and one 10-year-old) were also intramuscularly injected with testosterone propionate (TEP), and the T/E ratio exceeded the proposed limit for all of the collected samples.

The aim of the current study was to determine whether the urinary $\mathrm{T} / \mathrm{E}$ ratio could be used as an alternative approach to differentiate exogenous testosterone from that endogenously produced in castrate cattle. A survey study was also performed to assess the endogenous concentration values for $\alpha \mathrm{TE}$ and $\beta \mathrm{TE}$ in untreated steers. In addition, naturally incurred urine samples were used to determine the extent to which testosterone metabolites were conjugated to glucuronide and sulfate moieties after drug administration. Enzymatic hydrolysis conditions were studied using multivariate analysis and response surface methodology. The detection windows for the exogenous testosterone treatment were assessed for the treated animals in which the concentration of $\beta$ TE and the calculated T/E ratios were evaluated.

\section{Experimental}

\section{Standards}

Epitestosterone ( $\alpha$ TE) was acquired from Dr. Ehrenstopher (Augsburg, Germany); 17 $\beta$-testosterone ( $\beta$ TE) was purchased from LGC Standards (Augsburg, Germany); $17 \alpha$-methyltestosterone- $d_{3}$ (MTT- $d_{3}$ ) was obtained from Creative Proteomics (New York, USA) and 19-nortestosterone- $d_{3}$ was obtained from Cambridge Isotope Laboratories (Andover, USA).

Individual stock solutions and internal standards were prepared at an average concentration of $100 \mu \mathrm{g} \mathrm{mL}^{-1}$ in methanol (J.T. Baker, Center Valley, USA). Working solutions were prepared by mixing the individual stock solutions and diluting them to obtain the final concentration of $0.07 \mu \mathrm{g} \mathrm{mL}^{-1}$ for both $\alpha \mathrm{TE}$ and $\beta \mathrm{TE}$. The internal standards $17 \alpha$-methyltestosterone- $d_{3}$ (MTT- $d_{3}$ ) and $17 \beta$-nortestosterone- $d_{3}\left(\mathrm{NOR}-d_{3}\right)$ were prepared at concentrations of $0.10,0.40 \mu \mathrm{g} \mathrm{mL}^{-1}$, respectively.

\section{Chemicals}

All reagents were of analytical grade. Anhydrous sodium acetate was acquired from Vetec (Rio de Janeiro, 
Brazil). The enzyme $\beta$-glucuronidase derived from Helix pomatia, type HP-2, activity $\geq 100,000$ units $\mathrm{mL}^{-1}$, tris-hydroxymethyl aminomethane, and the solid phase extraction (SPE) column HLB (hydrophilic lipophilic balanced, $200 \mathrm{mg}, 6 \mathrm{~mL}$ ) were purchased from SigmaAldrich (St. Louis, USA). The SPE column amino (500 mg, $3 \mathrm{~mL}$ ) was acquired from Agilent Technologies (Waldbronn, Germany). The high-performance liquid chromatography (HPLC) grade solvents acetone, methanol, and tert-butyl methyl ether were purchased from J.T. Baker (Center Valley, USA). Sodium acetate buffer $\left(0.2 \mathrm{~mol} \mathrm{~L}^{-1}\right)$ was prepared by dissolving $16.4 \mathrm{~g}$ of anhydrous sodium acetate in $1000 \mathrm{~mL}$ ultrapure water; thereafter, the $\mathrm{pH}$ was adjusted to 5.2 by adding acetic acid (Sigma-Aldrich, St. Louis, USA). Ultrapure water was generated by Gehaka Master Sigma 100 (Gehaka, São Paulo, Brazil).

\section{Equipment}

High-performance liquid chromatography-tandem mass spectrometry (HPLC-MS/MS) analysis was performed using an Agilent Technologies 1200 series liquid chromatography system equipped with an autosampler and a quaternary pump (Agilent Technologies, Santa Clara, USA) coupled to a triple quadrupole mass spectrometer (API 5000, Applied Biosystems, Foster City, USA). Separation was achieved on a Poroshell 120 EC-C18 column $(50 \times 3.0 \mathrm{~mm}, 2.7 \mu \mathrm{m})$ (Agilent Technologies, Santa Clara, USA). The flow rate used was $0.700 \mathrm{~mL} \mathrm{~min}^{-1}$ and the column temperature was set at $40^{\circ} \mathrm{C}$. A gradient elution programmer was used with solvent A (ultrapure water) and solvent B (methanol) as follows: from 0 to $0.5 \mathrm{~min}$ the percentage of B was held at $60 \%$ and linearly increased to $80 \%$ at $2.0 \mathrm{~min}$; from 2.0 to $2.1 \mathrm{~min}$ this percentage linearly increased to $100 \%$, which was maintained until $2.5 \mathrm{~min}$, and from 2.5 to 4.00 linearly decreased to $60 \%$. From 4.0 to $6.0 \mathrm{~min}$, the B percentage was held constant at $60 \%$, and the injection volume was $10 \mu \mathrm{L}$. Detection was performed in selected reaction monitoring (SRM) mode. Instrumental control and data treatment were performed using Analyst 1.5.1 software (AB Sciex, Framingham, USA). The data acquisition used for the HPLC-MS/MS analysis is presented in Table 1.

\section{Sample extraction}

Urine samples were analyzed using an in-house ISO/IEC/17025:2017 25 accredited method that is regularly used in Brazil for the routine monitoring of bovine urine samples for 17 growth promoters as well as $\alpha \mathrm{TE}$ and $\beta$ TE. The extraction procedure was executed as follows: after the samples were thawed at room temperature, $100 \mu \mathrm{L}$ of the internal standard working solution, $2 \mathrm{~mL}$ of sodium acetate buffer $\left(2 \mathrm{~mol} \mathrm{~L}^{-1}, \mathrm{pH}=5.2\right)$ and $25 \mu \mathrm{L}$ of Helix pomatia juice were added to $5.0 \mathrm{~mL}$ of urine and incubated at $37{ }^{\circ} \mathrm{C}$ for $16 \mathrm{~h}$. Thereafter, $4 \mathrm{~mL}$ of tris-hydroxymethyl aminomethane solution $\left(2 \mathrm{~mol} \mathrm{~L}^{-1}, \mathrm{pH}=9.5\right)$ were added, and two consecutive liquid-liquid extractions with diethyl ether were performed. After evaporation, the residue was reconstituted with $4 \mathrm{~mL}$ of water/methanol $(2: 1 \mathrm{v} / \mathrm{v})$. The clean-up was performed using SPE with HLB and amino cartridges coupled. The former was pre-conditioned with $5 \mathrm{~mL}$ of methanol and $5 \mathrm{~mL}$ of acetone, and HLB with $5 \mathrm{~mL}$ of methanol and $5 \mathrm{~mL}$ of water. After elution with $5 \mathrm{~mL}$ of acetone and evaporation, the residue was reconstituted to $500 \mu \mathrm{L}$, and $10 \mu \mathrm{L}$ of the reconstituted residue was injected into the HPLC-MS/MS system. Together with the analyzed samples, matrix-matched calibration curves were prepared by adjusting the working solution at the beginning of the extraction procedure to obtain the following concentration values for $\alpha \mathrm{TE}$ and $\beta$ TE: $0.50,0.75,1.00,1.25,1.50$, and $2.00 \mu \mathrm{g} \mathrm{L}^{-1}$. The validated limits of detection and quantification were 0.25 and $0.50 \mu \mathrm{g} \mathrm{L}^{-1}$, respectively.

\section{Enzymatic hydrolysis study}

The evaluation of the extent of chemical conjugation of the studied analytes to glucuronide and sulfate moieties was performed using Helix pomatia juice. For the treated group,

Table 1. Data acquisition used to detect the testosterone metabolites and the internal standards by the selected reaction monitoring (SRM) mode

\begin{tabular}{|c|c|c|c|c|c|c|c|}
\hline Analyte & IS & Q1 & Q3 & Ion ratio / \% & $\mathrm{DP} / \mathrm{V}$ & $\mathrm{CE} / \mathrm{V}$ & $\mathrm{CXP} / \mathrm{V}$ \\
\hline \multirow{2}{*}{$\alpha \mathrm{TE}$} & \multirow{2}{*}{ NTT- $d_{3}$} & \multirow{2}{*}{289.2} & $97.0^{\mathrm{a}}$ & - & \multirow{2}{*}{56} & 33 & 18 \\
\hline & & & 109.0 & 91.2 & & 35 & 10 \\
\hline \multirow{2}{*}{$\beta \mathrm{TE}$} & \multirow{2}{*}{ MTT- $d_{3}$} & \multirow{2}{*}{289.2} & $97.1^{\mathrm{a}}$ & - & \multirow{2}{*}{60} & 37 & \multirow{2}{*}{12} \\
\hline & & & 109.1 & 93.3 & & 35 & \\
\hline MTT- $d_{3}$ & - & 306.3 & $97.0^{\mathrm{b}}$ & - & 111 & 39 & 20 \\
\hline NTT- $d_{3}$ & - & 278.5 & $109.1^{\mathrm{b}}$ & - & 85 & 36 & 18 \\
\hline
\end{tabular}

aQuantitative diagnostic ions; binternal standard diagnostic ions. IS: internal standard; Q1: parent ion; Q3: product ion; DP: declustering potential; CE: collision energy; CXP: collision cell exit potential; $\alpha$ TE: epitestosterone; $\beta$ TE: $17 \beta$-testosterone; MTT- $d_{3}: 17 \alpha$-methyltestosterone- $d_{3} ;$ NTT- $d_{3}: 19$-nortestosterone- $d_{3}$. 
four samples collected from each animal were combined to make $5 \mathrm{~mL}$ of urine. Six replicates were prepared, three of which were enzymatically digested for $16 \mathrm{~h}$ at $37.5^{\circ} \mathrm{C}$ with $50 \mu \mathrm{L}$ of the enzyme preparation. The estimated percentage of the unconjugated fraction $(\mathrm{P})$ was calculated by monitoring the unconjugated steroids ( $\alpha \mathrm{TE}$ and $\beta \mathrm{TE}$ ). Analytical curves were prepared using the hydrolysis reaction, to allow for the referencing of $100 \%$ of the set of samples subjected to Helix pomatia deconjugation. The corresponding $\mathrm{P}(\%)$ value was then obtained as a direct proportion of the obtained concentration values for the samples for which hydrolysis was not executed. The Student's $t$-value for comparison of means between the two sets was also calculated. A Box-Behnken design was used to assess the best reaction conditions for each analyte. The following factors were evaluated: enzyme volume $(-1)$ : 10 , (0): 50 , (1): $100 \mu \mathrm{L}$; reaction time (-1): 1.5 ; (0): 16; (1): $24 \mathrm{~h}$; and reaction temperature $(-1)$ : room temperature; (0): 37 ; (1): $55^{\circ} \mathrm{C}$. The calculated concentration values were statistically evaluated using analysis of variance $\left(\right.$ ANOVA) ${ }^{26}$ in Microsoft Excel $2010^{\circledR}$ software. ${ }^{27}$

\section{Survey study and detection window evaluation}

An in vivo study was performed on four crossbred steers treated with TEP (Androgenol ${ }^{\circledR}$, Hertape Calier, Juatuba, Brazil) in two consecutive doses of $0.2 \mathrm{mg} \mathrm{kg}^{-1}$. Urine samples were collected by spontaneous urination of the confined animals on the following days for the treated animals: $-5,-4,0$ (just before drug administration), $0+6 \mathrm{~h}$, $1,1+6 \mathrm{~h}, 2,3,3+6 \mathrm{~h}, 4,5,7,9,11$, and 14. A second set of four steers (C1-C4) was maintained without any drug treatment during the experiment, and urine samples were collected on days $-5,-4,1,9$, and 14 . The samples were centrifuged for $30 \mathrm{~min}$ at $2700 \mathrm{~g}$ and transferred to $50 \mathrm{~mL}$ plastic tubes, which were stored at $-80{ }^{\circ} \mathrm{C}$ for a maximum period of 10 days before extraction. This procedure was performed after approval by the Ethical Committee on Animal Experimentation of the Federal University of Minas Gerais, Brazil, according to protocol No. 111/2019.

\section{Results and Discussion}

Matrix-matched calibration curves were employed for the validated method, in which the analytical standards were adjusted at the beginning of the extraction procedure to obtain the following concentration levels: 0.70, 1.05, 1.40, $1.75,2.10$, and $2.80 \mu \mathrm{g} \mathrm{L}^{-1}$. After method validation, the accuracy levels were 76.5 and $86.4 \%$, and the coefficients of variation under intermediate precision conditions were 22.6 and $15.8 \%$ for $\alpha \mathrm{TE}$ and $\beta \mathrm{TE}$, respectively, which corresponds to adequate performance according to the adopted validation guide. ${ }^{1}$ The calculated decision limits (CC $\alpha$ ) were $0.22 \mu \mathrm{g} \mathrm{L}^{-1}$ for $\alpha \mathrm{TE}$ and $0.23 \mu \mathrm{g} \mathrm{L}^{-1}$ for $\beta \mathrm{TE}$, and the detection capabilities (CC $\beta$ ) were $0.48 \mu \mathrm{g} \mathrm{L}^{-1}$ for $\alpha \mathrm{TE}$ and $0.53 \mu \mathrm{g} \mathrm{L}^{-1}$ for $\beta \mathrm{TE}$.

\section{Enzymatic hydrolysis study}

Considering that phase II reactions such as glucuronidation and sulfation play an important role in the excretion metabolism of veterinary drugs in urine, ${ }^{21,23}$ the extent to which they are chemically bound is important for quantification purposes. Therefore, the use of naturally produced samples for the study of conjugation reactions is highly desirable, since the use of synthetic standards may not perfectly mimic the biological distribution of the conjugate species. The frequently performed hydrolysis conditions reported in the literature were initially used to assess its influence on the deconjugation reaction in urine (i.e., $16 \mathrm{~h}, 37^{\circ} \mathrm{C}, 50 \mu \mathrm{L}$ for urine). ${ }^{12,16,21}$ Table 2 presents the concentration values for $\alpha$ TE and $\beta$ TE obtained from urine samples that were subjected to the hydrolysis reaction, together with the estimated percentage of the unconjugated fraction for both analytes.

Table 2. Enzymatic hydrolysis evaluation of the testosterone metabolites in bovine urine

\begin{tabular}{lcccc}
\hline Analyte & $\mathrm{C}^{\mathrm{a}} /\left(\mu \mathrm{g} \mathrm{L}^{-1}\right)$ & $\mathrm{C}^{\mathrm{b}} /\left(\mu \mathrm{g} \mathrm{L}^{-1}\right)$ & $\mathrm{P} / \%$ & $\begin{array}{c}\text { Student } \\
t \text {-value }\end{array}$ \\
\hline$\alpha \mathrm{TE}$ & $0.42( \pm 0.01)$ & $2.73( \pm 0.03)$ & 15.5 & 121.1 \\
$\beta$ TE & $0.22( \pm 0.03)$ & $1.64( \pm 0.14)$ & 13.4 & 12.4 \\
\hline
\end{tabular}

${ }^{\mathrm{a} C} \mathrm{C}$ : calculated concentration obtained with no hydrolysis reaction; ${ }^{\mathrm{b}} \mathrm{C}$ : calculated concentration obtained after hydrolysis; P: estimated percentage of the unconjugated fraction; $\alpha$ TE: $17 \alpha$-testosterone; $\beta$ TE: $17 \beta$-testosterone.

The concentration values of $\alpha \mathrm{TE}$ and $\beta \mathrm{TE}$ were significantly lower in the absence of the hydrolysis reaction (13.4-15.5\%), and the calculated $t$ values at the $95 \%$ confidence level were greater than the critical value $\left(t_{(0.05 ; 4)}=2.77\right)$. Therefore, the hydrolysis reaction had a significant influence on the analysis of unconjugated testosterone metabolites in bovine urine. Therefore, a Box-Behnken design was used to study the influence of each reaction condition on the analytical responses of $\beta$ TE and $\alpha \mathrm{TE}$ (Table 2). The Box-Behnken design is a second-order multivariate design based on a threelevel incomplete factorial design with no axial points, which permits the assessment of the critical factors that significantly affect the analytical responses using a reduced number of experiments. ${ }^{28}$ The evaluated factors 
and the obtained concentration values for each test are presented in Table 3.

Table 3. Calculated concentrations for $17 \alpha$-testosterone ( $\alpha$ TE) and $17 \beta$-testosterone ( $\beta \mathrm{TE}$ ) obtained from the $3^{3}$ Box-Behnken Design for the enzymatic hydrolysis evaluation

\begin{tabular}{|c|c|c|c|c|c|}
\hline \multirow{2}{*}{ Experiment } & \multirow{2}{*}{$\begin{array}{l}\text { Enzyme } \\
\text { volume }\end{array}$} & \multirow{2}{*}{$\begin{array}{l}\text { Reaction } \\
\text { time }\end{array}$} & \multirow{2}{*}{$\begin{array}{c}\text { Reaction } \\
\text { temperature }\end{array}$} & \multicolumn{2}{|c|}{ Concentration / $\left(\mu \mathrm{g} \mathrm{L}^{-1}\right)$} \\
\hline & & & & $\alpha \mathrm{TE}$ & $\beta \mathrm{TE}$ \\
\hline 1 & -1 & -1 & 0 & 0.27 & 1.01 \\
\hline 2 & 1 & -1 & 0 & 0.65 & 1.49 \\
\hline 3 & -1 & 1 & 0 & 1.30 & 1.47 \\
\hline 4 & 1 & 1 & 0 & 3.90 & 1.65 \\
\hline 5 & -1 & 0 & -1 & 1.18 & 1.37 \\
\hline 6 & 1 & 0 & -1 & 2.97 & 1.75 \\
\hline 7 & -1 & 0 & 1 & 0.46 & 0.68 \\
\hline 8 & 1 & 0 & 1 & 2.75 & 2.04 \\
\hline 9 & 0 & -1 & -1 & 0.26 & 1.11 \\
\hline 10 & 0 & 1 & -1 & 2.36 & 1.48 \\
\hline 11 & 0 & -1 & 1 & 0.46 & 1.13 \\
\hline 12 & 0 & 1 & 1 & 1.33 & 1.63 \\
\hline 13 & 0 & 0 & 0 & 2.66 & 1.73 \\
\hline 14 & 0 & 0 & 0 & 2.86 & 1.76 \\
\hline 15 & 0 & 0 & 0 & 2.85 & 1.64 \\
\hline
\end{tabular}

Enzyme volume (-1): 10, (0): 50, (1): $100 \mu \mathrm{L}$; reaction time (-1): 1.5, (0): $16,(1): 24 \mathrm{~h}$; reaction temperature (-1): room temperature, $(0): 37^{\circ} \mathrm{C}$, (1): $55{ }^{\circ} \mathrm{C}$; $\alpha \mathrm{TE}$ : $17 \alpha$-testosterone; $\beta \mathrm{TE}$ : $17 \beta$-testosterone.

The quality of the adjustments was evaluated by ANOVA, in which the respective mean square values for lack of fit and pure error were divided to obtain a calculated $F$-value. The response surfaces obtained for $\alpha \mathrm{TE}$ and $\beta \mathrm{TE}$ are shown in Figure 1.

The statistical models did not present evidence of lack of fit at the $95 \%$ confidence level, since the calculated $F$ values (9.84 for $\alpha \mathrm{TE}$ and 15.09 for $\beta \mathrm{TE}$ ) were lower than $F_{\text {critical }(0.05 ; 3 ; 2)}=19.16$. The respective equations to describe the concentration values $(\mathrm{C})$ related to the studied factors volume $(\mathrm{V})$, temperature $(\mathrm{T})$, and time $(\mathrm{t})$ are represented in equations 1 and 2 :

$$
\begin{aligned}
& \mathrm{C}_{\alpha \mathrm{TE}}=(2.79 \pm 0.06)+(0.88 \pm 0.04) \mathrm{V}+(0.91 \pm 0.04) \mathrm{t}- \\
& (0.22 \pm 0.04) \mathrm{T}-(0.26 \pm 0.06) \mathrm{V}^{2}-(1.00 \pm 0.06) \mathrm{t}^{2}- \\
& (0.69 \pm 0.06) \mathrm{T}^{2}+(0.55 \pm 0.06) \mathrm{VT}-(0.31 \pm 0.06) \mathrm{tT}
\end{aligned}
$$

$\mathrm{C}_{\beta \mathrm{TE}}=(1.71 \pm 0.04)+(0.30 \pm 0.02) \mathrm{V}+(0.19 \pm 0.02) \mathrm{t}-$

$(0.21 \pm 0.03) \mathrm{t}^{2}-(0.16 \pm 0.06) \mathrm{T}^{2}+(0.24 \pm 0.03) \mathrm{VT}$

Temperature had the least influence on the curvature of the obtained response surfaces. In contrast, volume and time significantly influenced the deconjugation process in such a way that the maximum values were located around the greater factors $(24 \mathrm{~h}$ and $100 \mu \mathrm{L})$. However, the central point condition $\left(50 \mu \mathrm{L}, 16 \mathrm{~h}\right.$, and $\left.37^{\circ} \mathrm{C}\right)$, which require a lower enzyme volume and a faster reaction, did not lead to significantly lower concentration values; therefore, this combination is an option for use on a routine basis, whereas the experiments using $10 \mu \mathrm{L}$ of enzyme and $1.5 \mathrm{~h}$ exhibited poorer performance and thereby should be avoided.

\section{Survey study and detection window evaluation}

The endogenous levels of $\alpha \mathrm{TE}$ and $\beta \mathrm{TE}$ were assessed by analyzing urine samples collected from the treated group before drug administration, and for the control group throughout the experiment. Table 4 presents the estimated concentration values obtained for both isomers, in which the treated animals were denoted as T1-T4, and the untreated animals as $\mathrm{C} 1-\mathrm{C} 4$. The alpha epimer $\alpha \mathrm{TE}$ was observed at greater intensities than $\beta \mathrm{TE}$ for all of the collected urine samples, which corroborates the literature,,$^{15}$ although $\beta \mathrm{TE}$ was not detected in the vast majority of urine samples collected from the untreated steers, probably because of their castrate condition. The methods reported in the literature describe endogenous testosterone as dependent on the animal age and gender, ${ }^{14,15,24}$ and an aim of this work was to establish that animal castration should also be evaluated when dealing with testosterone monitoring. Here, the calculation of the T/E ratio to assess a cut-off limit for a control group of animals was not possible, and most of the concentrations obtained for both isomers were lower than the validated LOQ $\left(0.50 \mu \mathrm{g} \mathrm{mL}^{-1}\right)$, which is equal or inferior to other reported limits found in the literature. ${ }^{14,15,24}$ However, it should be noted that the method validation and applicability were developed in the frame of the European Decision 657/2002/EC, ${ }^{1}$ which recommends that any result above the $\mathrm{CC} \alpha$ of the method should be reported for prohibited drugs. According to this regulation, the CC $\alpha$ is used to define the limit above which it can be concluded that a sample contains the analyte, with an error probability of $\alpha$ equal to $1 \%$ (probability of false noncompliant decision) for prohibited drugs. This means that $\mathrm{CC} \alpha$ is the lowest concentration level at which a method can discriminate whether the identified analyte is present. $\mathrm{CC} \beta$ is the lowest concentration of a compound that may be detected, identified, and quantified in a sample, with an error probability of $\beta$ equal to $5 \%$ (probability of falsecompliant results). Therefore, since this work deals with the detection of hormone abuse, the concentration values above the respective $\mathrm{CC} \alpha$ values for $\alpha \mathrm{TE}$ and $\beta \mathrm{TE}, 0.22$ and $0.23 \mu \mathrm{g} \mathrm{L}^{-1}$, were reported as estimated concentration values.

As for the monitoring of both testosterone isomers 

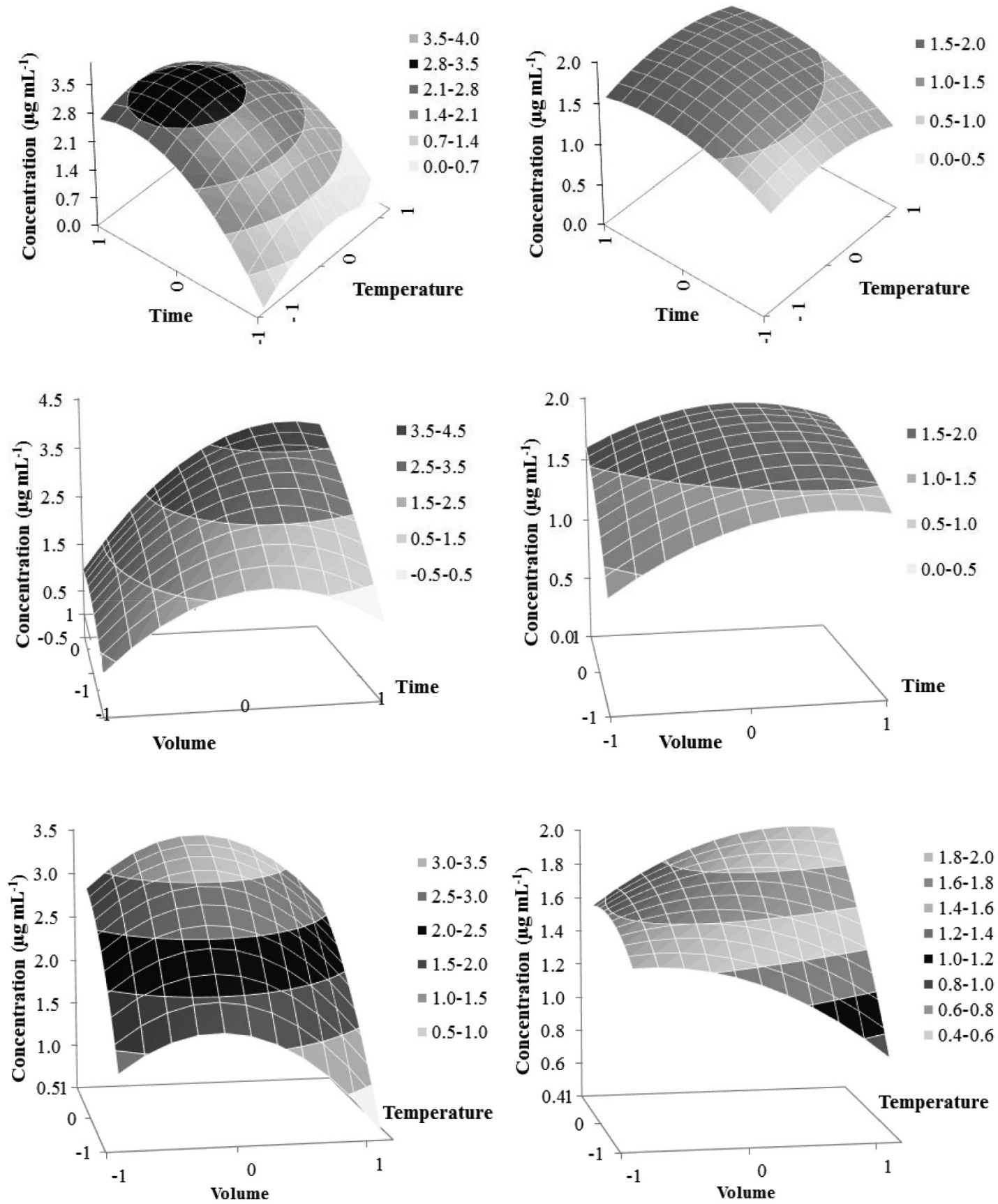

Figure 1. Response surfaces obtained for $\alpha \mathrm{TE}$ and $\beta \mathrm{TE}$ from a $3^{3}$ Box-Behnken design for the evaluation of the enzymatic hydrolysis conditions using Helix pomatia.

after drug administration, Figure 2 shows the extracted ion chromatograms for $\alpha \mathrm{TE}$ and $\beta \mathrm{TE}$ from day 0-14 after testosterone treatment for $\mathrm{T} 1$.

$\beta$ TE was rapidly observed after $6 \mathrm{~h}$ of drug administration, and its analytical signal was detected for 11 days. For the other three animals, a similar pattern was observed, in which the detection windows for $\beta \mathrm{TE}$ were 7 days for $\mathrm{T} 2$ and $\mathrm{T} 4$, and 11 days for T3. Figure 3 shows the calculated $\beta$ TE concentrations and T/E ratios obtained from the urine samples. The concentration values for each sample are presented in Table S1 (Supplementary Information section).

A period of 3 days occurred between the application of the testosterone formulation and a decay to lower levels, which is in agreement with the package leaflet instructions. Although $\beta$ TE was not detected before drug administration, illegal treatment could not be attributed to the treated samples due to the known endogenous nature of this compound. Therefore, the applicability of the T/E ratio was evaluated to characterize the exogenous use, in which higher oscillations 
Table 4. Detection of the metabolites $17 \alpha$-testosterone ( $\alpha \mathrm{TE})$ and $17 \beta$-testosterone $(\beta \mathrm{TE})$ in urine samples of untreated steers

\begin{tabular}{|c|c|c|c|c|c|c|c|c|}
\hline \multirow{2}{*}{ Collection day } & \multicolumn{8}{|c|}{$\beta \mathrm{TE} /\left(\mu \mathrm{g} \mathrm{mL}^{-1}\right)$} \\
\hline & $\mathrm{T} 1$ & $\mathrm{~T} 2$ & $\mathrm{~T} 3$ & $\mathrm{~T} 4$ & $\mathrm{C} 1$ & $\mathrm{C} 2$ & $\mathrm{C} 3$ & $\mathrm{C} 4$ \\
\hline-5 & 0.26 & ND & ND & $0.34^{\mathrm{a}}$ & $0.49^{\mathrm{a}}$ & 0.58 & ND & ND \\
\hline-4 & ND & ND & ND & ND & $0.45^{\mathrm{a}}$ & ND & ND & ND \\
\hline 0 & ND & ND & ND & 0.52 & ND & 0.70 & ND & ND \\
\hline 1 & - & - & - & - & ND & ND & ND & $0.29^{\mathrm{a}}$ \\
\hline 9 & - & - & - & - & ND & ND & $0.29^{\mathrm{a}}$ & ND \\
\hline \multirow[t]{3}{*}{14} & - & - & - & - & ND & ND & $0.43^{\mathrm{a}}$ & ND \\
\hline & \multicolumn{8}{|c|}{$\alpha \mathrm{TE} /\left(\mu \mathrm{g} \mathrm{mL}^{-1}\right)$} \\
\hline & $\mathrm{T} 1$ & $\mathrm{~T} 2$ & $\mathrm{~T} 3$ & $\mathrm{~T} 4$ & $\mathrm{C} 1$ & $\mathrm{C} 2$ & $\mathrm{C} 3$ & $\mathrm{C} 4$ \\
\hline-5 & $0.43^{\mathrm{a}}$ & $0.34^{\mathrm{a}}$ & $0.25^{\mathrm{a}}$ & $0.29^{\mathrm{a}}$ & $0.45^{\mathrm{a}}$ & ND & 0.70 & $0.43^{\mathrm{a}}$ \\
\hline-4 & $0.38^{\mathrm{a}}$ & $0.28^{\mathrm{a}}$ & $0.35^{\mathrm{a}}$ & $0.26^{\mathrm{a}}$ & $0.49^{\mathrm{a}}$ & $0.29^{\mathrm{a}}$ & 0.56 & $0.33^{\mathrm{a}}$ \\
\hline 0 & $0.32^{\mathrm{a}}$ & $0.30^{\mathrm{a}}$ & $0.36^{\mathrm{a}}$ & $0.36^{\mathrm{a}}$ & $0.47^{\mathrm{a}}$ & $0.33^{\mathrm{a}}$ & $0.46^{\mathrm{a}}$ & $0.47^{\mathrm{a}}$ \\
\hline 1 & $0.41^{\mathrm{a}}$ & $0.39^{\mathrm{a}}$ & $0.24^{\mathrm{a}}$ & ND & $0.41^{\mathrm{a}}$ & ND & 0.54 & 0.51 \\
\hline 9 & $0.48^{\mathrm{a}}$ & $0.31^{\mathrm{a}}$ & $0.27^{\mathrm{a}}$ & ND & $0.22^{\mathrm{a}}$ & ND & 0.50 & $0.42^{\mathrm{a}}$ \\
\hline 14 & $0.37^{\mathrm{a}}$ & $0.43^{\mathrm{a}}$ & $0.29^{\mathrm{a}}$ & $0.28^{\mathrm{a}}$ & $0.30^{\mathrm{a}}$ & $0.31^{\mathrm{a}}$ & 0.62 & $0.36^{\mathrm{a}}$ \\
\hline
\end{tabular}

${ }^{a}$ Estimated concentration values lower than LOQ but greater than CC $\alpha$. ND: no detection; $\alpha$ TE: $17 \alpha$-testosterone; $\beta$ TE: $17 \beta$-testosterone.
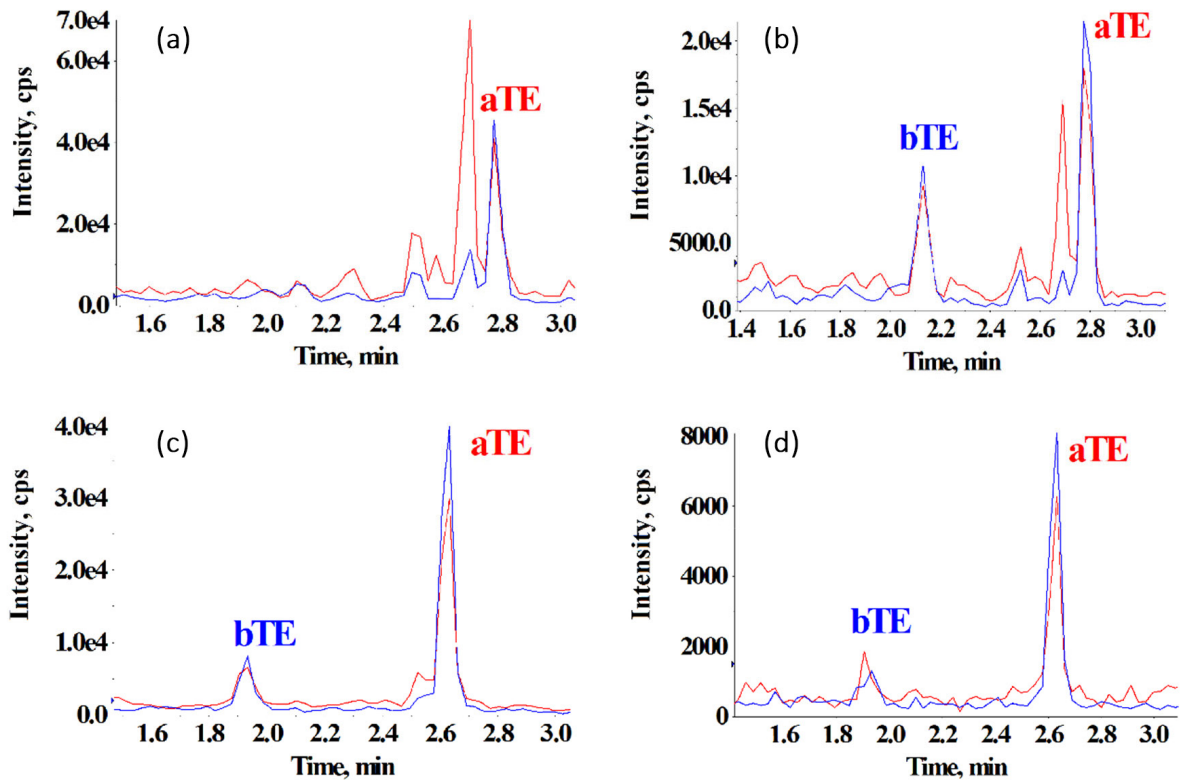

Figure 2. Extracted ion chromatograms (quantitative and qualitative ion transitions) related to the variation on the intensities between $\beta T E$ (bTE) and $\alpha \mathrm{TE}$ (aTE) for the animal T1 at (a) day 0; (b) day $0+6 \mathrm{~h}$; (c) day 11, and (d) day 14.

over the treatment were observed for $\mathrm{T} 2$ and $\mathrm{T} 4$ (Figure 2). However, for T1, the drug treatment did not significantly alter this value over the study period, even after the second dose was administered on day 3. It should be noted that for most of the reported studies, the $\mathrm{T} / \mathrm{E}$ ratios were greater than 1 for treated animals, with cut-off limits in the range of 4 to 6 . However, these ratios were calculated when high $\beta$ TE concentrations were obtained (around $15 \mathrm{ppb}$ ), which did not occur in any of the samples in this work..$^{14,16}$

As an outcome of this study, it can be seen that the T/E ratio could be useful for sample treatment classification in castrate cattle, since high values are suggestive of exogenous treatment, whereas low or non-existent values of $\beta T E$ were detected in the untreated castrated animals. The decision limit for this analyte was equal to $0.23 \mu \mathrm{g} \mathrm{mL}^{-1}$, which indicated that the endogenous concentrations should be lower than this value. The method described in this article was developed for use in a surveillance program by the Ministry of Agriculture, Livestock, and Supply of Brazil for the monitoring of prohibited veterinary drugs. Thus, the identification of high levels of $17 \beta$-testosterone in urine samples collected from castrated cattle can be classified 

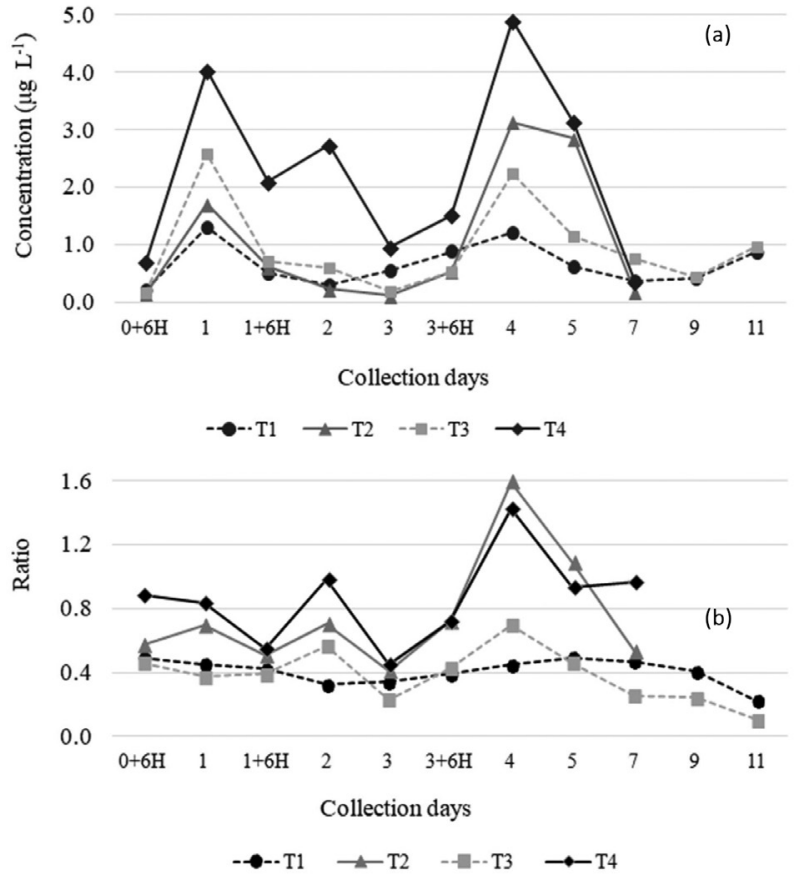

Figure 3. Calculated $\beta T E$ concentrations (a) and T/E ratios (b) in urine for the four steers subjected to the testosterone treatment.

as suspicious with regard to non-compliance with growth promoter regulations. Since the exogenous use would still be inconclusive, the laboratory report could contain this information, with an additional request for forensic work, such as in loco farm/slaughterhouse inspections. This work could be executed through interviews, searches for used packages, package inserts and syringes, or by other strategies to trace/prevent drug abuse.

\section{Conclusions}

In this study, naturally incurred urine samples containing testosterone propionate metabolites were obtained for an animal experiment involving castrate cattle, which is a condition particularly common in livestock. It could be observed that $\beta \mathrm{TE}$ and $\alpha \mathrm{TE}$ were predominantly present in conjugate forms in urine. The enzymatic hydrolysis reaction was studied using response surface methodology, in which a central point condition led to satisfactory performance. Few samples collected from untreated animals exhibited detectable $\beta$ TE signals, which were observed in the treated group up to 11 days after drug administration. In contrast, aTE was detected in most of the control animals and all of the treated steers. Considering that the beta isomer was observed only after drug treatment, high levels of this analyte could be related to possible drug abuse in castrate cattle. The application of the T/E ratio between both testosterone isomers was also studied; however, the absence of $\beta$ TE for the control group halted the establishment of a cut-off level based on an untreated population. To the best of our knowledge, this is the first time that this ratio has been evaluated for castrate cattle.

\section{Supplementary Information}

Supplementary information (Table S1) is available free of charge at http://jbcs.sbq.org.br as PDF file.

\section{Acknowledgments}

The authors would like to acknowledge the Fundação de Amparo à Pesquisa do Estado de Minas Gerais (process: CAGAPQ-01049-15) and the Coordenação de Aperfeiçoamento de Pessoal de Nível Superior (CAPES) for financial support. The authors are grateful to Laboratório Federal de Defesa Agropecuária (LFDA-MG), at the Ministério da Agricultura, Pecuária e Abastecimento (MAPA) of Brazil, for providing its infrastructure and supplies for the development of this work. The authors also thank the assistance of the Postgraduate Collegiate in Animal Science at the Universidade Federal de Minas Gerais (UFMG) for providing the funds for the publication of the article.

\section{References}

1. European Commission; Commission Decision of 12 August 2002 implementing Council Directive 96/23/EC Concerning the Performance of Analytical Methods and the Interpretation of Results (2002/657EC); Official Journal of the European Union, 2002, L221, p. 8-36, available at https://eur-lex.europa. eu/legal-content/EN/TXT/HTML/?uri=CELEX:32002D0657\& from=EN, accessed in November 2021.

2. European Commission; Council Directive 96/23/EC of 29 April 1996 on Measures to Monitor Certain Substances and Residues thereof in Live Animals and Animal Products and Repealing Directives 85/358/EEC and 86/469/EEC and Decisions 89/187/ EEC and 91/664/EEC; Official Journal of the European Union, 1996, L125, p. 10-32, available at https://eur-lex.europa.eu/ legal-content/EN/TXT/HTML/?uri=CELEX:31996L0023\&fr om=EN, accessed in November 2021.

3. Gonzalez Ronquillo, M.; Angeles Hernandez, J. C.; Food Control 2017, 72, 255.

4. Janssens, G.; Mangelinckx, S.; Courtheyn, D.; de Kimpe, N.; Matthijs, B.; le Bizec, B.; J. Agric. Food Chem. 2015, 63, 7574.

5. van Meulebroek, L.; Wauters, J.; Pomian, B.; Bussche, J. V.; Delahaut, P.; Fichant, E.; Vanhaecke, L.; PLoS One 2018, 13, e0195351.

6. Narduzzi, L.; Dervilly, G.; Marchand, A.; Audran, M.; Le Bizec, B.; Buisson, C.; Drug Test. Anal. 2020, 12, 887.

7. Toutain, P. L.; Handb. Exp. Pharmacol. 2010, 199, 315. 
8. Elmongy, H.; Masquelier, M.; Ericsson, M.; J. Chromatogr. A 2020, 1613.

9. Kaabia, Z.; Laparre, J.; Cesbron, N.; Le Bizec, B.; DervillyPinel, G.; J. Steroid Biochem. Mol. Biol. 2018, 183, 106.

10. Kaabia, Z.; Dervilly-Pinel, G.; Popot, M. A.; Bailly-Chouriberry, L.; Plou, P.; Bonnaire, Y.; Le Bizec, B.; Drug Test. Anal. 2014, 6, 376.

11. Narduzzi, L.; Dervilly, G.; Audran, M.; Le Bizec, B.; Buisson, C.; Drug Test. Anal. 2020, 12, 677.

12. Scarth, J. P.; Kay, J.; Teale, P.; Akre, C.; Le Bizec, B.; De Brabander, H. F.; Vanhaecke, L.; Van Ginkel, L.; Points, J.; Drug Test. Anal. 2012, 4, 40.

13. Pozo, O. J.; Marcos, J.; Ventura, R.; Fabregat, A.; Segura, J.; Anal. Bioanal. Chem. 2010, 398, 1759.

14. Viljanto, M.; Scarth, J.; Hincks, P.; Hillyer, L.; Cawley, A.; Suann, C.; Noble, G.; Walker, C. J.; Kicman, A. T.; Parkin, M. C.; Drug Test. Anal. 2017, 9, 1328.

15. Angeletti, R.; Contiero, L.; Gallina, G.; Montesissa, C.; Vet. Res. Commun. 2006, 30, 127.

16. Waller, C. C.; McLeod, M. D.; Drug Test. Anal. 2017, 9, 1304.

17. Ferchaud, V.; Courcoux, P.; Le Bizec, B.; Monteau, F.; André, F.; Analyst 2000, 125, 2255.

18. Tamae, D.; Byrns, M.; Marck, B.; Mostaghel, E. A.; Nelson, P. S.; Lange, P.; Lin, D.; Taplin, M. E.; Balk, S.; Ellis, W.; True, L.; Vessella, R.; Montgomery, B.; Blair, I. A.; Penning, T. M.; J. Steroid Biochem. Mol. Biol. 2013, 138, 281.
19. Impens, S.; Van Loco, J.; Degroodt, J. M.; De Brabander, H.; Anal. Chim. Acta 2007, 586, 43.

20. Kaklamanos, G.; Theodoridis, G.; Dabalis, T.; J. Chromatogr. B: Anal. Technol. Biomed. Life Sci. 2009, 877, 2330.

21. Pizzato, E. C.; Filonzi, M.; da Rosa, H. S.; de Bairros, A. V.; Toxicol. Mech. Methods 2017, 27, 641.

22. Kotronoulas, A.; Marcos, J.; Segura, J.; Ventura, R.; Joglar, J.; Pozo, O. J.; Anal. Chim. Acta 2015, 895, 35.

23. Pedersen, M.; Frandsen, H. L.; Andersen, J. H.; Food Addit. Contam., Part A 2017, 34, 482.

24. Snoj, T.; Dolenc, J.; Kobal, S.; Food Addit. Contam., Part A 2014, 31, 614 .

25. ABNT NBR ISO/IEC 17025:2017: Requisitos Gerais para a Competência de Laboratórios de Ensaio e Calibração, ABNT: Rio de Janeiro, 2005.

26. Rocha, D. G.; Santos, F. A.; Augusti, R.; Faria, A. F.; J. Braz. Chem. Soc. 2016, 27, 221.

27. Gates III, W. H.; Allen, P. G.; Microsoft Excel software; Microsoft Corporation, Redmond, Washington, United States, 2010.

28. Montgomery, D. C.; Design and Analysis of Experiments, $4^{\text {th }}$ ed.; Willey: New York, USA, 1997.

Submitted: April 25, 2021

Published online: November 23, 2021 